\title{
Evaluation of drug information resources for interactions between therapeutic drugs and drugs of abuse
}

\author{
Robert D. Beckett; Jennifer R. Martin; Curtis D. Stump; Megan A. Dyer
}

See end of article for authors' affiliations.

\begin{abstract}
Objective: The study evaluated point-of-care resources for scope, completeness, and consistency of information describing interactions between therapeutic drugs and drugs of abuse (DoA).

Methods: A cross-sectional evaluation study was conducted focusing on seven resources: Clinical Pharmacology, Facts \& Comparisons eAnswers, Lexicomp Online, Micromedex, Drug Interactions Analysis and Management, Drug Interaction Facts, and Stockley's Drug Interactions. A sample of clinically relevant interactions was developed through review of tertiary literature and resources, and input was solicited from subject matter experts. Entries from each resource for each interaction were evaluated for scope (i.e., whether there was an entry for the interaction); completeness (i.e., whether there was information addressing mechanism; clinical effects, severity, course of action, and level of certainty, described as a median rating on a 5-point scale); and consistency (i.e., whether the information in the resource was similar to the majority) among resources with an entry.
\end{abstract}

Results: Following review by subject matter experts, the final sample contained 159 interactions. Scope scores ranged from 0.6\% (Drug Interactions Analysis and Management) to 43.4\% (Lexicomp Online). Completeness scores ranged from 2 (interquartile range [IQR] 0 to 3, Stockley's Drug Interactions) to 5 (IQR 5 to 5, Drug Interaction Facts, Micromedex, Facts \& Comparisons eAnswers). Consistency scores ranged from 30.8\% (Stockley's Drug Interactions) to $87.1 \%$ (Clinical Pharmacology) for severity and from $15.4 \%$ (Facts \& Comparisons eAnswers) to $71.4 \%$ (Drug Interaction Facts) for course of action.

Conclusions: Although coverage of drug-DoA interactions was low and content was often inconsistent among resources, the provided information was generally complete.

\section{INTRODUCTION}

In 2018, 53.2 million Americans used illicit drugs, including cannabis, cocaine, crack cocaine, hallucinogens, heroin, inhalants, methamphetamine, and prescription stimulants [1]. Opioid misuse has been an epidemic in the United States, with 10.3 million users 12 years of age or older in the past year $[2,3]$. Many drugs of abuse, whether legalized or not, possess clinically relevant interactions with therapeutic medications that could increase risk for adverse safety events or decrease therapeutic effectiveness of the prescribed drug [4]. Identifying and mitigating risk from these interactions is critical for protecting patient safety, and having appropriate, evidence-based information to guide health care professionals is essential.

Previous studies have evaluated content from tertiary drug information resources describing common drug-drug [5-8], drug-ethanol [9], and drug-tobacco interactions [9]. There have also been studies focusing on subgroups of drug-drug interactions involving psychiatric [10] and intensive 
care-related drugs [8]. However, none of these studies have addressed interactions between therapeutic drugs and drugs of abuse (DoA). The purpose of this study is to evaluate key point-of-care resources for scope and completeness and consistency of drug-DoA interaction information.

\section{METHODS}

A cross-sectional evaluation study of seven tertiary, point-of-care drug information resources was conducted. Resources were selected based on a review of the American Association of Colleges of Pharmacy Library and Information Sciences guidance document, Basic Resources for Pharmacy Education [11], and for consistency with two similar published studies [7, 9]. The four commercially available electronic resources were Clinical Pharmacology powered by the ClinicalKey Drug Interaction Report (Clinical Pharmacology), Facts \& Comparisons eAnswers Interactions (Facts \& Comparisons), Lexicomp Online Interactions (Lexicomp Online), and IBM Micromedex Drug Interactions (Micromedex) [12-15]. The three print resources were Drug Interactions Analysis and Management (2014), Drug Interaction Facts (2015), and Stockley's Drug Interactions (eleventh edition) [16-18].

A sample of clinically relevant drug-DoA interactions was developed using a systematic PubMed search to yield results indexed to Medical Subject Headings (MeSH) for illicit drugs and drug interactions. Results were filtered to yield review articles. The search was conducted by an experienced pharmacy librarian. Articles were reviewed, and interactions that were described as clinically relevant were extracted. Drugs of Abuse (second edition) was also reviewed [4]. The list of potential interactions was shared with two subject matter experts: a neuropharmacologist and a board-certified clinical pharmacy specialist in psychiatry, both of whom teach in the DoA area. Subject matter experts were asked to review the list and recommend necessary additions or removals in order to generate a sample of the most clinically relevant interactions. Based on the methods of similar studies, a sample of 100 to 200 interactions was deemed to be sufficient for a valid assessment of the resources in terms of the end points. Interactions were selected if they resulted in potential safety concerns or decreased effectiveness of the therapeutic drug (as opposed to the DoA) $[7,9]$.

Data were extracted from each resource by two investigators using a standard, electronic data collection form, with any discrepancies resolved by consensus with a third investigator, who is a boardcertified clinical pharmacy specialist in pharmacotherapy and a drug information specialist.

The following data points were gathered for each interaction from each resource: mechanism, potential clinical effects of the interaction, severity rating, recommended course of action, and level of certainty (Table 1) [7, 9]. Investigators coded severity as minor, moderate, major, or severe/contraindicated. Course of action was coded as no action; monitor, counsel, or inform; adjust dose or administration; or avoid concomitant use. The most serious severity rating or highest level course of action was used in the event that there were multiple ratings or courses of action for the same interaction.

Similar to previous studies, 3 key endpoints were assessed: scope, completeness, and consistency (Table 1) $[7,9]$. Scope was defined as the percentage of interactions that possessed an entry in the resource. Completeness was defined for each data extraction element (i.e., mechanism, clinical effects, severity, course of action, level of certainty) as the percentage of interactions that contained the information. An overall completeness score was calculated by summing points for the 5 data extraction elements (i.e., 1 point per element, to yield a score of 0 to 5 possible points for each interaction, for each resource) and then calculating the median score by resource.

Consistency was defined as the percentage of interactions in each resource with content that was similar to the majority of resources. For example, if a resource rated an interaction as "major" in severity, and the majority of resources used the same rating, the first resource would be considered consistent with the rest. However, it would not be considered consistent if it rated the interaction as "minor." Consistency was determined using severity and course of action, as the most objectively codable data extraction elements. 
DOI: dx.doi.org/10.5195/jmla.2020.969

Table 1 Collected data points and endpoints

\begin{tabular}{|c|c|c|c|}
\hline & & Data point & Endpoint \\
\hline Scope & & $\begin{array}{l}\text { Entry for the interaction in the } \\
\text { resource }\end{array}$ & $\begin{array}{l}\text { Percentage of interactions with an } \\
\text { entry }\end{array}$ \\
\hline \multirow[t]{6}{*}{ Completeness } & Mechanism & $\begin{array}{l}\text { Pharmacological explanation for } \\
\text { how the interaction occurs }\end{array}$ & $\begin{array}{l}\text { Percentage of interactions with } \\
\text { unambiguous mechanism information }\end{array}$ \\
\hline & $\begin{array}{l}\text { Clinical effects of the } \\
\text { interaction }\end{array}$ & $\begin{array}{l}\text { Signs and/or symptoms indicative } \\
\text { of the interaction }\end{array}$ & $\begin{array}{l}\text { Percentage of interactions with } \\
\text { unambiguous clinical effects } \\
\text { information }\end{array}$ \\
\hline & Severity rating & $\begin{array}{l}\text { Potential seriousness of the } \\
\text { interaction, if it occurs }\end{array}$ & $\begin{array}{l}\text { Percentage of interactions with } \\
\text { unambiguous severity information }\end{array}$ \\
\hline & $\begin{array}{l}\text { Recommended course } \\
\text { of action }\end{array}$ & $\begin{array}{l}\text { Recommended intervention to } \\
\text { mitigate interaction risk }\end{array}$ & $\begin{array}{l}\text { Percentage of interactions with } \\
\text { unambiguous course of action } \\
\text { information }\end{array}$ \\
\hline & Level of certainty & $\begin{array}{l}\text { Level of documentation supporting } \\
\text { the interaction }\end{array}$ & $\begin{array}{l}\text { Percentage of interactions with } \\
\text { unambiguous level of certainty } \\
\text { information }\end{array}$ \\
\hline & Overall & $\begin{array}{l}1 \text { point awarded for each } \\
\text { completeness element, per } \\
\text { interaction, per resource }\end{array}$ & Median score on a scale of 0 to 5 points \\
\hline \multirow[t]{2}{*}{ Consistency } & Severity & $\begin{array}{l}\text { Severity ratings, coded as minor, } \\
\text { moderate, major, or } \\
\text { severe/contraindicated }\end{array}$ & $\begin{array}{l}\text { Percentage of interactions with the } \\
\text { same severity coding as the majority of } \\
\text { resources }\end{array}$ \\
\hline & Course of action & $\begin{array}{l}\text { Recommended course of action, } \\
\text { coded as no action; monitor, } \\
\text { counsel, or inform; adjust dose or } \\
\text { administration; avoid concomitant } \\
\text { use }\end{array}$ & $\begin{array}{l}\text { Percentage of interactions with the } \\
\text { same course of action coding as the } \\
\text { majority of resources }\end{array}$ \\
\hline
\end{tabular}

Descriptive statistics (percentage for nominal data, medians with interquartile range [IQR] for ordinal data) were primarily used to describe results for scope, completeness, and consistency. A tier analysis was also conducted to group resources by similar scope and completeness scores. The highest scoring resource was compared to the next highest scoring resource, serially, until the difference in score was statistically significant using a prespecified alpha value of 0.05 . Once a difference was found to be statistically significant, the lower scoring resource formed the beginning of a new tier, and the process was continued in the same manner.

The McNemar test was used for scope scores (nominal data) and the Wilcoxon signed-rank test was used for completeness scores (ordinal data). Statistical tests for paired data were selected because the same sample of interaction pairs was used to evaluate each resource. Tier analysis was not conducted for consistency results, since two distinct consistency measures were considered (i.e., severity and course of action) and given missing data from instances when only one or two resources had entries for the information. Inferential statistics were conducted using IBM SPSS, version 24 [19].

\section{RESULTS}

The initial literature search identified 169 drug-DoA interactions. Following review by subject matter experts, a final sample of 159 interaction pairs was formed. The primary reason for removal was if the interaction would have resulted in decreased "effectiveness" of the DoA (i.e., the therapeutic drug would have decreased the levels or activity of the DoA). The final sample, organized by DoA, is available in the supplemental appendix. 
Of the 159 interaction pairs in the sample, 69 (43.4\%) had an entry in Lexicomp Online, 68 (42.8\%) had entries in Clinical Pharmacology and Stockley's Drug Interactions, 28 (17.6\%) had an entry in Micromedex, 24 (15.1\%) had an entry in Facts \& Comparisons, 7 (4.4\%) had an entry in Drug Interaction Facts, and $1(0.6 \%)$ had an entry in Drug Interactions Analysis and Management. The scope tier analysis led to formation of 3 tiers: tier 1 (Lexicomp Online, Clinical Pharmacology, Stockley's Drug Interactions; $p<0.001$ versus all remaining resources); tier 2 (Micromedex, Facts \& Comparisons; $p<0.001$ versus all remaining resources); and tier 3 (Drug Interaction Facts, Drug Interactions Analysis and Management).

Completeness results, in terms of the 5 specific completeness elements and overall completeness scores, are provided in Table 2. Drug Interactions Analysis and Management is not included in these results, as well as in the consistency results, since there was only a single interaction pair available from it for analysis (it provided information for mechanism, clinical effects, and course of action, but not severity or level of certainty). The completeness tier analysis led to formation of 4 tiers: tier 1 (Drug
Interaction Facts, Micromedex, Facts \& Comparisons; median 5, IQR 5 to $5 ; p<0.001$ versus all remaining resources); tier 2 (Lexicomp Online; median 4, IQR 4 to $5 ; p<0.001$ versus all remaining resources); tier 3 (Clinical Pharmacology; median 4, IQR 4 to 4; $p=0.001$ versus the remaining resource); and tier 4 (Stockley's Drug Interactions; median 2, IQR 0 to 3).

Consistency scores are provided in Table 3. Consistency scores ranged from 30.8\% (Stockley's Drug Interactions) to $87.1 \%$ (Clinical Pharmacology) for severity and from $15.4 \%$ (Facts \& Comparisons) to $71.4 \%$ (Drug Interaction Facts) for course of action.

\section{DISCUSSION}

This study reported, for the first time, the quality of the information describing drug-DoA interactions available from standard, point-of-care, tertiary references. Overall, the scope of available information was low, with no resource having an entry for more than half of the interaction sample. However, the information that was available was generally very thorough. Completeness was highest for Drug Interaction Facts, Micromedex, and Facts \& Comparisons.

Table 2 Completeness elements and overall scores by resource

\begin{tabular}{|c|c|c|c|c|c|c|c|c|c|c|c|c|c|}
\hline \multirow[b]{2}{*}{ Resource } & \multirow[b]{2}{*}{$\mathbf{n}$} & \multicolumn{2}{|c|}{ Mechanism* } & \multicolumn{2}{|c|}{$\begin{array}{l}\text { Clinical } \\
\text { effects* }\end{array}$} & \multicolumn{2}{|c|}{ Severity* } & \multicolumn{2}{|c|}{$\begin{array}{c}\text { Level of } \\
\text { certainty }\end{array}$} & \multicolumn{2}{|c|}{$\begin{array}{c}\text { Course of } \\
\text { action }^{*}\end{array}$} & \multicolumn{2}{|c|}{$\begin{array}{c}\text { Completeness } \\
\text { score } f\end{array}$} \\
\hline & & $\mathbf{n}$ & $(\%)$ & $\mathbf{n}$ & $(\%)$ & $\mathrm{n}$ & $(\%)$ & $\mathbf{n}$ & $(\%)$ & n & $(\%)$ & $\mathbf{n}$ & range \\
\hline $\begin{array}{l}\text { Clinical } \\
\text { Pharmacology }\end{array}$ & 68 & 67 & $(98.5 \%)$ & 67 & $(98.5 \%)$ & 69 & $(100.0 \%)$ & 3 & $(4.4 \%)$ & 59 & $(86.8 \%)$ & 4 & $(4$ to 4$)$ \\
\hline $\begin{array}{l}\text { Drug } \\
\text { Interaction } \\
\text { Facts }\end{array}$ & 7 & 7 & $(100.0 \%)$ & 7 & $(100.0 \%)$ & 7 & $(100.0 \%)$ & 7 & $(100.0 \%)$ & 7 & $(100.0 \%)$ & 5 & (5 to 5$)$ \\
\hline $\begin{array}{l}\text { Facts \& } \\
\text { Comparisons }\end{array}$ & 24 & 23 & $(95.8 \%)$ & 24 & $(100.0 \%)$ & 24 & $(100.0 \%)$ & 24 & $(100.0 \%)$ & 24 & $(100.0 \%)$ & 5 & (5 to 5$)$ \\
\hline $\begin{array}{l}\text { Lexicomp } \\
\text { Online }\end{array}$ & 69 & 38 & $(55.1 \%)$ & 58 & $(84.1 \%)$ & 69 & $(100.0 \%)$ & 69 & $(100.0 \%)$ & 69 & $(100.0 \%)$ & 4 & (4 to 5$)$ \\
\hline Micromedex & 28 & 28 & $(100.0 \%)$ & 28 & $(100.0 \%)$ & 28 & $(100.0 \%)$ & 28 & $(100.0 \%)$ & 27 & $(96.4 \%)$ & 5 & (5 to 5$)$ \\
\hline $\begin{array}{l}\text { Stockley's } \\
\text { Drug } \\
\text { Interactions }\end{array}$ & 68 & 32 & $(47.1 \%)$ & 32 & $(47.1 \%)$ & 17 & $(25.0 \%)$ & 12 & $(17.6 \%)$ & 29 & $(42.6 \%)$ & 2 & (0 to 3$)$ \\
\hline
\end{tabular}

* $\mathrm{n}(\%)$; percentage of interaction pairs with clear, unambiguous information for the element.

† median (IQR); 1 point assigned for each completeness element; potential range 0 to 5 for each interaction pair. 
DOI: dx.doi.org/10.5195/jmla.2020.969

Table 3 Consistency scores by resource

\begin{tabular}{|c|c|c|c|c|}
\hline \multirow[b]{2}{*}{ Resource } & \multicolumn{2}{|c|}{ Severity consistency* } & \multicolumn{2}{|c|}{ Course of action consistency $\dagger$} \\
\hline & Score & $(\%)$ & Score & $(\%)$ \\
\hline Clinical Pharmacology & $54 / 62$ & $(87.1 \%)$ & $29 / 55$ & $(52.7 \%)$ \\
\hline Drug Interaction Facts & $3 / 7$ & $(42.9 \%)$ & $5 / 7$ & $(71.4 \%)$ \\
\hline Facts \& Comparisons & $9 / 15$ & $(60.0 \%)$ & $2 / 13$ & $(15.4 \%)$ \\
\hline Lexicomp Online & $54 / 65$ & $(83.1 \%)$ & $24 / 57$ & $(42.1 \%)$ \\
\hline Micromedex & $10 / 24$ & $(41.7 \%)$ & $9 / 23$ & $(39.1 \%)$ \\
\hline Stockley's Drug Interactions & $4 / 13$ & $(30.8 \%)$ & $6 / 14$ & $(42.9 \%)$ \\
\hline
\end{tabular}

* Calculated as the percentage of available severity ratings for the resource that were similar to the majority of resources (e.g., out of 62 entries in Clinical Pharmacology with a severity rating, 54 (87.1\%) were similar to the majority of the assessed resources).

† Calculated as the percentage of available course of action recommendations for the resource that were similar to the majority of resources (e.g., out of 55 entries in Clinical Pharmacology with a course of action rating, 29 (52.7\%) were similar to the majority of the assessed resources).

Consistency was highly variable. Clinical Pharmacology and Lexicomp Online scored highest for consistency of severity ratings, while Drug Interaction Facts and Micromedex were most consistent for recommended course of action. Validity of results for completeness and consistency might be limited by the lower scope scores, which decreased the number of interactions available for analysis. Drug Interaction Facts, in particular, only had seven interactions available for analysis.

These results echo a previous study that examined drug-ethanol and drug-tobacco interactions [9]. For drug-ethanol interactions in particular, the resources that contained the most complete information were also Lexicomp, Micromedex, Drug Interaction Facts, and Facts \& Comparisons. This same study identified Micromedex as providing the most complete information on drug-tobacco interactions and found similar overall results for completeness and scope of information. To date, no other studies have evaluated point-of-care resources or open access tools such as National Drug File: Reference Terminology (NDF-RT) and DrugBank for drugDoA interactions $[5-8,10,20]$.

Drug interaction detection software can detect harmful interactions and is available through several commercial sources. Some of the most commonly utilized commercial software among drug information experts are Micromedex, Lexicomp, and Facts \& Comparisons [21, 22]. According to Grizzle et al., the most commonly used commercially available databases for detecting potential drug- drug interactions were Lexicomp and Micromedex, which were evaluated in a study [22]. Results from that study also revealed that other used resources included UpToDate Drug Interactions (containing the same information as Lexicomp), Epocrates, and Clinical Pharmacology, in addition to a few open access information resources such as Drugs@FDA and DailyMed [22]. This study did not evaluate Epocrates since it was not recognized in Basic Resources in Pharmacy Education [11]. This study did not use prescribing information from Drugs@FDA or DailyMed, because of their lack of a specific interaction checking tool and the importance of offlabel information in evaluating interaction risk.

A limitation of this study was that only seven references were evaluated, and none were open access. However, the four primary commercially available drug information databases were represented, and selection of resources was based on expert guidelines and previously published studies $[7,9]$. Based on previous surveys, the top preferred resources that would provide off-label information on drug-DoA interactions were evaluated in this study [21, 22]. It should be noted that differences in completeness scores were often driven by the levelof-certainty element. If a resource did not have a systematic heading that addressed this element, it might not have been as easy to detect the relevant content. Additionally, two resources, Clinical Pharmacology and Stockley's Drug Interactions, did not consistently provide a recommended course of action. Lack of this key element could hinder health care professionals' confidence in using the resource to aid them in clinical decision-making. 
Results from this study can be used to help librarians and drug information specialists prioritize and justify subscriptions during times of scarce resources. They can also help improve efficiency when responding to questions from patrons, patients, or health care professionals or when recommending resources to these individuals. For example, it was anecdotally noted in these results that Stockley's Drug Interactions appeared to disproportionately cover Schedule I drugs, compared to other resources. Classroom or experiential instruction on drug interactions, from clinical or information mastery perspectives, can be greatly enhanced by the knowledge of which resources to use during specific situations. Future similar studies could continue to systematically explore drug interactions content by examining drug-food, drug-laboratory, drug-pregnancy, and drug-dietary supplement interactions. The quality of available information is also unknown for other types of drug information, such as pregnancy and lactation and off-label use content.

This study provides an overview of drug-DoA interactions of several key tertiary resources. Although coverage of drug-DoA was low and content was often inconsistent among resources, the provided information was generally complete. Overall, these results can be used in education, collection management, and clinical practice to help guide users to the best resources based on the information that is needed.

\section{ACKNOWLEDGMENTS}

The investigators thank Thomas R. Smith, PharmD, $\mathrm{BCPP}$, and Shekher Mohan, PhD for their aid in developing the sample of drug-DoA interactions.

\section{DATA AVAILABILITY STATEMENT}

Data from this study can be located in Open Science Framework at https:// osf.io/m79v6.

\section{REFERENCES}

1. Arellano AL, Papaseit E, Romaguera A, Torrens M, Farre $M$. Neuropsychiatric and general interactions of natural and synthetic cannabinoids with drugs of abuse and medicines. CNS Neurol Disord Drug Targets. 2017;16(5):554--66. DOI: http://dx.doi.org/10.2174/1871527316666170413104516.
2. Pérez-Mañá C, Papaseit E, Fonseca F, Farré A, Torrens M, Farré M. Drug interactions with new synthetic opioids. Front Pharmacol. 2018 Oct;9:1145. DOI: http://dx.doi.org/10.3389/fphar.2018.01145.

3. Substance Abuse and Mental Health Services Administration Services (SAaMH). Key substance use and mental health indicators in the United States: results from the 2018 national survey on drug use and health [Internet]. Rockville, MD: The Administration; 2019 [cited 23 Oct 2019]. <https:// www.samhsa.gov/data/report/2018nsduh-annual-national-report>.

4. Wills S. Drugs of abuse. 2nd ed. Grayslake, IL: Pharmaceutical Press; 2015.

5. Abarca J, Malone DC, Armstrong EP, Grizzle AJ, Hansten PD, Van Bergen RC, Lipton RB. Concordance of severity ratings provided in four drug interaction compendia. J Am Pharm Assoc. 2004 Mar-Apr;44(2):136-41. DOI: http://dx.doi.org/10.1331/154434504773062582.

6. Malone DC, Abarca J, Hansten PD, Grizzle AJ, Armstrong EP, Van Bergen RC, Duncan-Edgar BS, Solomon SL, Lipton RB. Identification of serious drug-drug interactions: results of the partnership to prevent drug-drug interactions. J Am Pharm Assoc. 2004 Mar-Apr;44(2):142-51. DOI: http://dx.doi.org/10.1331/154434504773062591.

7. Patel RI, Beckett RD. Evaluation of resources for analyzing drug interactions. J Med Libr Assoc. 2016 Oct;104(4):290-5. DOI: http:/ / dx.doi.org/10.3163/1536-5050.104.4.007.

8. Wagh BR, Godbole DD, Deshmukh SS, Iyer S, Deshpande PR. Identification and assessment of potential drug-drug interactions in intensive care unit patients. Indian J Crit Care Med. 2019 Apr;23(4):170-4. DOI: http://dx.doi.org/10.5005/jp-journals-10071-23147.

9. Beckett RD, Stump CD, Dyer MA. Evaluation of drug information resources for drug-ethanol and drug-tobacco interactions. J Med Libr Assoc. 2019 Jan;107(1):62-71. DOI: http://dx.doi.org/10.5195/jmla.2019.549.

10. Monteith S, Glenn T. A comparison of potential psychiatric drug interactions from six drug interaction database programs. Psychiatry Res. 2019 May;275:366-72. DOI: http://dx.doi.org/10.1016/i.psychres.2019.03.041.

11. Guy J, Portillo I, eds. Basic resources for pharmacy education [Internet]. Arlington, VA: American Association of Colleges of Pharmacy 2019 [rev. Jul 2019; cited 23 Jun 2020].

$<$ https://connect.aacp.org/HigherLogic/System/Downl oadDocumentFile.ash $x$ ?DocumentFileKey $=3 \mathrm{~d} 70 \mathrm{ed} 16-$ cb20-c959-26fe-ddcd6f768c8d\&forceDialog=0>.

12. Gold S, Elsevier. Clinical pharmacology drug interaction report [Internet]. Amsterdam, The Netherlands: Elsevier; 2019 [cited 30 Jul 2019]. <http://www.clinicalpharmacologyip.com/Forms/Reports/intereport.aspx>.

13. Wolters Kluwer. Facts \& Comparisons $®$ eAnswers [Internet]. Indianapolis, IN: Wolters Kluwer [cited 30 Jul 2019]. <http://online.factsandcomparisons.com/>.

14. Wolters Kluwer. Lexicomp ${ }^{\circledR}$ Interactions [Internet]. Indianapolis, IN: Wolters Kluwer [cited 30 Jul 2019]. <http://online.lexi.com/lco/action/interact>. 
15. IBM. Micromedex® Solutions Drug Interactions [Internet]. Armonk, NY: IBM [cited 30 Jul 2019]. $<$ https://www.micromedexsolutions.com>.

16. Hansten PD, Horn JR. Drug interactions analysis and management. St. Louis, MO: Wolters Kluwer Health; 2014.

17. Tatro DS, ed. Drug interaction facts 2015. St. Louis, MO: Wolters Kluwer Health; 2014.

18. Baxter K, Preston CL, eds. Stockley's drug interactions. London, UK: Pharmaceutical Press; 2016.

19. IBM Analytics I. SPSS Statistics. Version 24. Armonk, NY: IBM; 2016.

20. Peters LB, Bahr N, Bodenreider O. Evaluating drug-drug interaction information in NDF-RT and DrugBank. J Biomed Semantics. 2015 May;6:19. DOI: http://dx.doi.org/10.1186/s13326-015-0018-0.

21. Roblek T, Vaupotic T, Mrhar A, Lainscak M. Drug-drug interaction software in clinical practice: a systematic review. Eur J Clin Pharmacol. 2015 Feb;71(2):131-42. DOI: http:/ / dx.doi.org/10.1007/s00228-014-1786-7.

22. Grizzle AJ, Horn J, Collins C, Schneider J, Malone DC, Stottlemyer B, Boyce RD. Identifying common methods used by drug interaction experts for finding evidence about potential drug-drug interactions: web-based survey. J Med Internet Res. 2019 Jan;21(1):e11182. DOI:

http://dx.doi.org/10.2196/11182.

\section{SUPPLEMENTAL FILE}

- Appendix: Sample of drug-drugs of abuse (DoA) interaction pairs

\section{AUTHORS' AFFILIATIONS}

Robert D. Beckett, rdbeckett@manchester.edu, Drug Information Center, Manchester University, Fort Wayne, IN

Jennifer R. Martin, jenmartin@arizona.edu, Health Sciences Library, University of Arizona, Tucson, AZ

Curtis D. Stump, CDStump2018@manchester.edu, Pharmacy Program, Manchester University, Fort Wayne, IN

Megan A. Dyer, MADyer2018@manchester.edu, Pharmacy Program, Manchester University, Fort Wayne, IN

Received March 2020; accepted June 2020

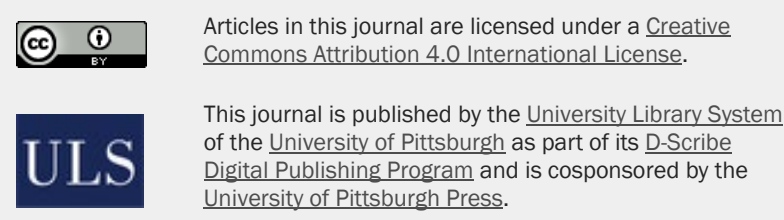

ISSN 1558-9439 (Online) 